\title{
Impact of COVID-19 Lockdowns on Australian Primary and Secondary School Students' Online Learning Experiences
}

\author{
Damian Maher ${ }^{10}$ \\ Centre for Research on Education in a Digital Society, University of Technology Sydney, Sydney, Australia \\ Email: Damian.Maher@uts.edu.au
}

Received: 28 July 2021; Revised: 24 August 2021; Accepted: 30 August 2021

\begin{abstract}
The impact of COVID-19 has seen many schools across the globe transition from face-to-face teaching to emergency remote teaching in a short period of time. This has impacted the quality of students' educational experiences. The study reported here draws on data collected from students, teachers, and parents in eight schools in New South Wales, Australia using a qualitative approach including surveys, and draws a Community of Inquiry framework to understand the experiences of students. Results of the study showed that social impacts were extensive and that limited interactions resulted in the loss of engagement and motivation for a majority of students who also reported a high level of understanding of what was expected of them but felt the workload was too high. It is suggested that more time be provided for social engagement to support motivation and engagement.
\end{abstract}

Keywords: community of practice, COVID-19, technology-enhanced learning, social connections, emergency remote teaching, motivation

\section{Introduction}

Approximately 100 years ago, many parts of the world were ravaged by the Spanish flu. As a result of this, many schools worldwide were closed. According to Rich (2020), during this period, there was little schoolwork completed. In 2020, 1.725 billion students globally were affected by the closure of schools and higher education institutions and 194 countries have implemented nationwide closures, affecting about $92 \%$ of the world's student population (UNESCO, n.d.).

One of the major differences today compared to 100 years ago is the use of the internet to support remote learning. Whilst access to the internet varies across countries, developed countries have high levels of access to the internet. In Australia for example, according to the Australian Bureau of Statistics (2018), 97\% of households with children under the age of 15 had internet access at home. However, this level of access is not consistent across all households.

While many young people in schools were not able to physically go to schools, they could still participate in schoolwork and have contact with their peers and teachers through Emergency Remote Teaching (ERT). Hodges et al. (2020) state ERT comprises: "Well-planned online learning experiences are meaningfully different from courses offered online in response to a crisis or disaster". For example, through ERT, the curriculum is redesigned in a hurry with minimal resources and scant time.

The purpose of this article is to investigate student experiences during the ERT period, where video conferencing (VC) and learner management systems (LMS) were used to connect students with content, teachers, and other students.

Copyright (C2021 Damian Maher.

DOI: https://doi.org/10.37256/ser.2220211062

This is an open-access article distributed under a CC BY license

(Creative Commons Attribution 4.0 International License)

https://creativecommons.org/licenses/by/4.0/ 
Eight schools in New South Wales, Australia, including primary, secondary, and one K-12 school, participated, where teachers, students, and parents completed online surveys during a lockdown that lasted for several months necessitating a temporary shift from a blended learning environment (where students were in school full time and connected at home to learner management systems) to learning that was exclusively online.

The study set out to answer the following research questions:

1. What were the online learning experiences of students during a lockdown?

2. What were the teachers' and parents' experiences of supporting the students?

\section{Literature review}

As a result of schools physically closing and learning shifting to online mode during the lockdown, changes were made to the way teaching and learning was undertaken. According to Ahmed (2020), technology is one way that education could be supported through the pandemic. As he states: "it can be seen with each passing day that how teachers, who were once mostly accustomed to the physical classroom and face to face interaction(s) are moving forward to adopt new methods of e-teaching and e-learning" (p. 243).

One of the issues of moving completely to an online environment is that the emotional well-being of school students can be negatively affected. Much of the material online, either in reports or in published articles tended to focus on this aspect. In an Australian study conducted with 1200 primary and secondary teachers, it was reported that $75 \%$ of the primary and secondary school teachers surveyed believed remote learning would negatively affect students' emotional well-being to some degree. "This would manifest in forms such as anxiety (including obsessive-compulsive disorder related to personal cleanliness), feelings of disconnection, withdrawal from interacting with others, and missing friends" (Ziebell et al., 2020, p. 7).

Psychological distress such as anxiety and depression amongst students may increase as students start to lose school connectedness, including a loss or lessening of the belief that both adults and peers in their school care about their learning as well as them as an individual (Pikulski et al., 2020). UNESCO (2020) recommends that there must be solutions to address psychosocial challenges of the pandemic, and this is a priority before teaching; describing the necessity to "ensure regular human interactions, enable social caring measures, and address possible psychosocial challenges that students may face when they are isolated" (UNESCO, 2020).

Another issue that has been brought into focus for students learning completely online is that of motivation and engagement. Engagement is important for students as it is central for effective learning, student success and wellbeing (Fredericks et al., 2004). Disengaged students are reported to be at risk of lower academic and poorer social outcomes (Hancock \& Zubrick, 2015). Studies conducted focusing on learning during COVID-19 have reported high levels of engagement and motivation for students although these studies have been conducted with adult learners (e.g., Gares et al., 2020).

Motivation has been shown to be an important aspect for school students to encourage their investment in schoolwork (Peetsma \& Van der Veen, 2015). Di Pietro et al. (2020) examined the literature around COVID-19 focusing on motivation for secondary school students and found students may be motivated to learn knowing their work would be assessed.

One aspect that was identified in analysing the data for this research was that of learner control. Like much of the literature discussed in this section, much of it focuses on higher education. Cahapay (2020), who discusses new ways of conceptualising education post-COVID-19, cites Huang et al. (2009), who discuss a blended learning approach and set out learner control consisting of time, setting, and pace. Carter et al. (2020) discussed K-12 students' learning in online environments to support remote learning with online and digital tools during the COVID-19 pandemic. These authors commented that: "In fact, many parents enroll their children in online learning because they want decision-making power in their learning, and safety from affective threats such as bullying, rather than more structure in the content" (p. 323).

The significance of this study is that it adds to the knowledge on the affordances and limitations of using the internet to mediate learning for students in times of lockdowns. In particular, this article highlights the views of students, drawing on a number of different schools, in relation to learning online. The opinions of teachers and parents are drawn upon as a way of understanding the experiences of the students. 


\section{Theoretical framework}

The theoretical framework that is used to analyse the data in this study is the Community of Inquiry model. The framework is influenced by the work of John Dewey and draws on a constructivist approach to learning (Garrison \& Arbaugh, 2007). The framework consists of three key elements: cognitive presence, social presence, and teaching presence (Garrison et al., 2001). It is through the interactions in all three elements that students are able to experience meaningful learning. Figure 1 sets out the elements.

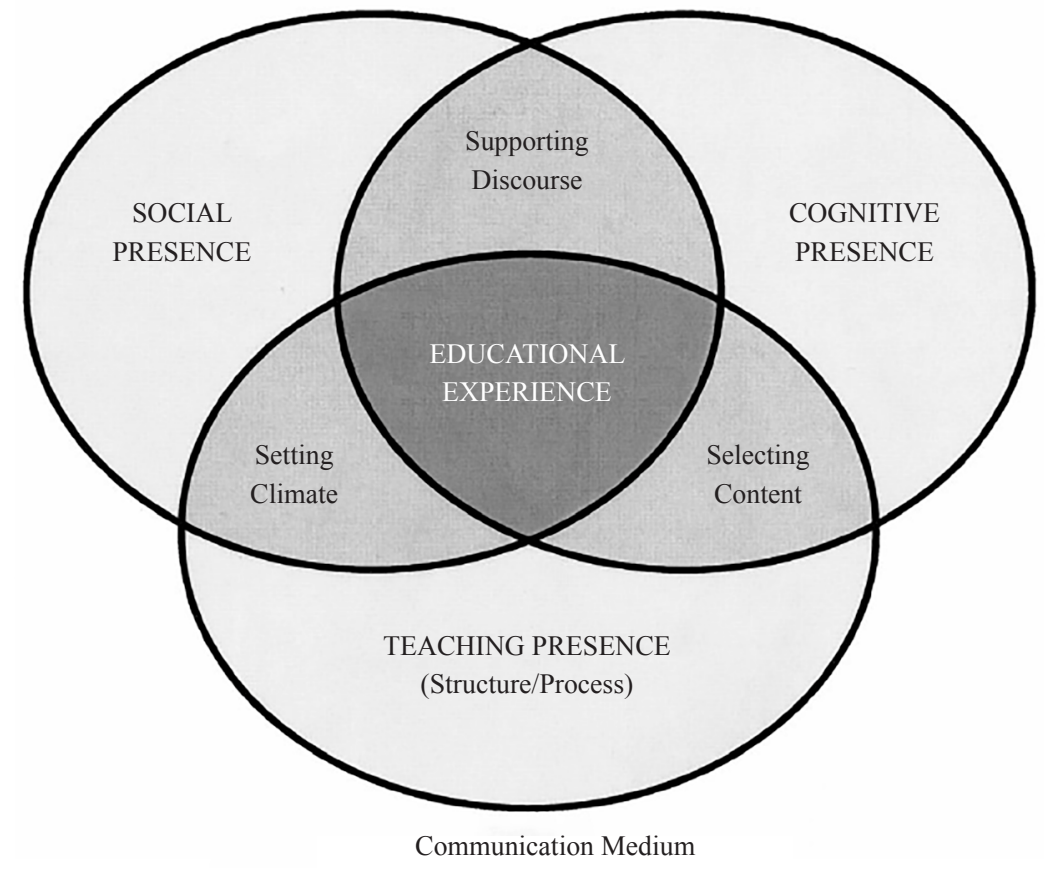

Figure 1. The community of inquiry model (Garrison et al., 2000)

Cognitive presence is the process of "collaboratively constructing meaning and confirming understanding in a sustainable community of inquiry" (Garrison, 2007, p. 4). The importance of facilitation to maintain the construction of knowledge and interaction by means of discourse production is highlighted. Additionally, cognitive presence refers to the extent to which online learners can construct and validate meanings based on communication and thinking.

"Social presence reflects the ability to establish and engage in purposeful relationships" (Bourke, 2019, p. 21). Such a presence is important as it builds intimacy, immediacy, and relationships among participants (Belderrain, 2006) which helps to develop a sense of being together with others and having a sense of engagement with them (Biocca et al., 2001). In an online environment, aspects such as face-to-face interactions (Bambara et al., 2009), which include the use of facial expressions and verbal expression (Lee \& Wagner, 2002), are aspects that contribute towards a sense of social presence.

Teaching presence involves the "design, facilitation, and direction of cognitive and social processes to realize personally meaningful and educationally worthwhile learning outcomes" (Anderson et al., 2001). It comprises two elements. The first element is the design of the educational experience, including the selection, organisation, and presentation of the course content (Lowenthal \& Parscal, 2008). The second element involves facilitation "for the purpose of constructing meaningful and worthwhile knowledge" (Garrison et al., 2000, p. 92). 


\section{Materials and methods}

The study used qualitative methodology (Lincoln \& Guba, 1985) to understand the experiences of participants (Hennink et al., 2011). An interpretive framework was used to analyse the data. Central to such a framework is the understanding that people's social world can be accessed through their lived experiences (Mason, 2002) and that the researcher's role is to interpret those experiences.

The methodology in this qualitative study is a multi-site case study approach (Audet \& d'Amboise, 2001). Case studies allow for a detailed study of a particular bounded phenomenon and retain a common focus across sites (Wiersma \& Jurs, 2005). In this study, the case is a primary/secondary community consisting of students', teachers', and parents' experiences of student learning entirely online as a result of COVID-19 restrictions.

\subsection{Participants}

All students, teachers, and parents at eight schools were invited to take part in the research project. A total of 573 participants completed the surveys, including primary, secondary, and central schools (P-12). Table 1 below provides a breakdown of how many participated in each group from the different schools.

Table 1. Participant details (pseudonyms used here and through the article)

\begin{tabular}{ccccc}
\hline School/participant numbers & teacher & student & parent & Total \\
\hline Balamara Girls High School & 12 & 22 & 56 & 90 \\
Lowan Boys High School & 15 & 3 & 4 & 22 \\
Malloga Girls High School & 5 & 12 & 32 & 49 \\
Narracan Primary School & 8 & 9 & 29 & 46 \\
Sandly Secondary College & 15 & 47 & 71 & 133 \\
Ukamirra High School & 18 & 46 & 44 & 108 \\
Ukala Primary School & 12 & 0 & 8 & 20 \\
Ulamba Central School & 4 & 13 & 88 & 105 \\
Total & 89 & 152 & 332 & 573 \\
\hline
\end{tabular}

Six of the schools were in metropolitan Sydney. Ulamba Central School and Ukamirra High School were in rural settings.

\subsection{Data collection and analysis}

The New South Wales (NSW) Primary Principals' Association and the NSW Secondary Principals' Council were approached to send out invitations to schools to participate. Given that schools in NSW were in lockdown at the time of the study, online surveys were undertaken with teachers, students and parents. Students from year 4 to 12 were invited to complete the survey as well as all parents and teachers who were teaching online. The surveys provided insights into participants' perspectives and practices (Nunan, 1992) and covered a broad range of ideas (Sandelowski, 2000). The student survey consisted of 4 contextual questions and 19 questions about studying online full time. The teacher survey consisted of 3 contextual questions and 16 questions about teaching online. The parent survey consisted of 4 contextual questions and 10 questions about their children's online learning.

Some questions required participants to provide written feedback and others required a response via Likert scale. The student survey had more Likert scale questions than parent or teacher surveys. The purpose of more Likert scale questions for students was to ensure ease in answering questions. The surveys were developed through consultation 
with school teachers focusing on aspects that were important in understanding how students were experiencing online learning.

In analysing the data, a thematic analysis approach (Boyatzis, 1998) was utilised. The data were coded using the 3 categories of community of practice outlined above (Garrison et al., 2000). Coding is the process of categorising and sorting data (Charmaz, 1983). The codes were then developed into themes. In order to diminish the risk of subjective interference with the emerging results, a number of measures were adopted including cross-checking the codes emerging from the responses, and discussion of emerging themes.

\section{Results and discussion}

This section firstly sets out some statistical information relating to students' access to computers and their level of experience of online learning. This is followed by an analysis and discussion of the data using the three categories of the Community of Inquiry framework.

The students were asked if they owned a computer. Across seven schools, $95.7 \%$ of students indicated they owned their own computer. The lowest level of ownership was for Ulamba Central School (which is in a rural setting) where the level was $83 \%$.

Students were asked if the quality of the internet allowed them to successfully complete their schoolwork. Figure 2, below, displays the results showing some variation across the schools with Malloga High School, a Sydney urban school, being reported as having the lowest quality.

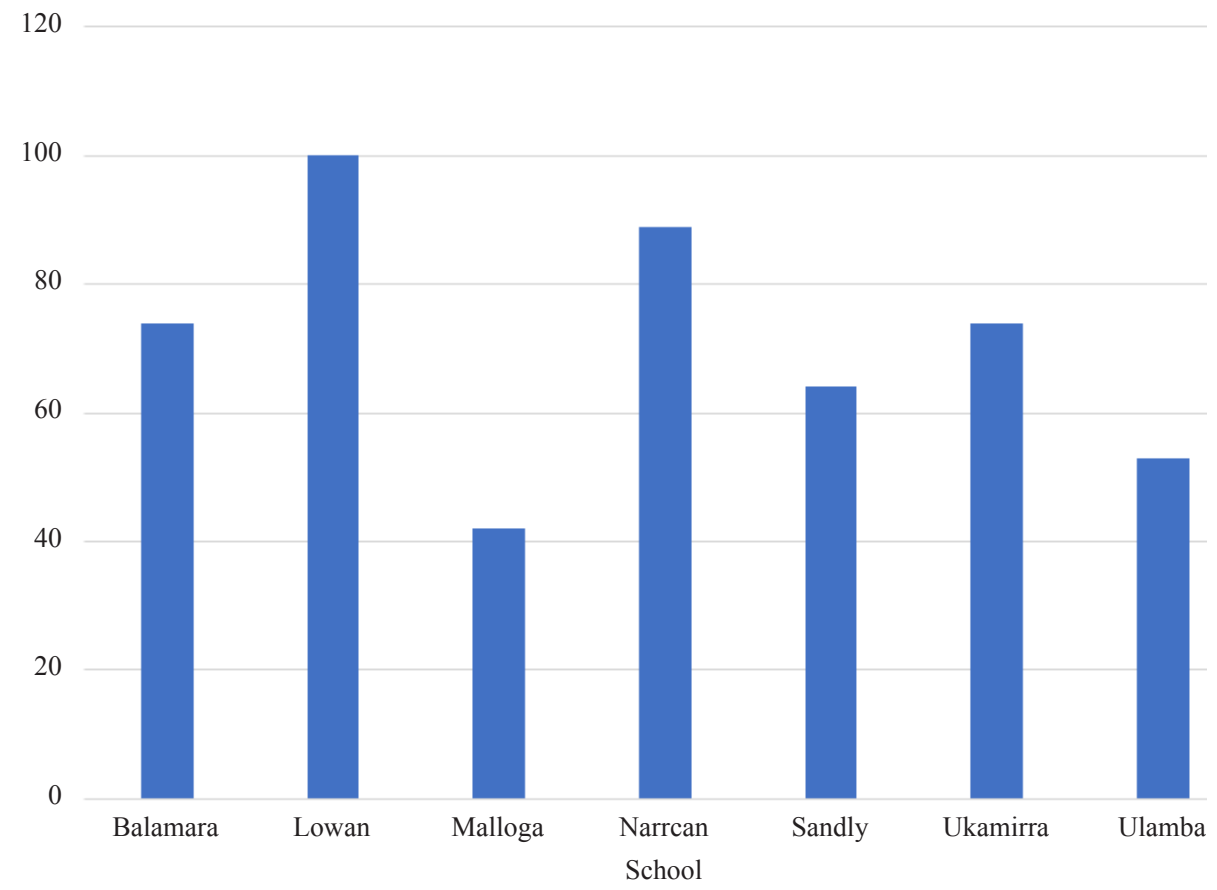

Figure 2. Quality of internet

With the exception of Malloga school, and to a lesser extent Ulamba school, the quality of the internet was considered satisfactory. Australia ranks approximately $50^{\text {th }}$ to $70^{\text {th }}$, in a worldwide comparison of internet speeds with an average of 40 megabytes per second broadband speed. One report has it ranked as the fourth slowest in Organisation for Economic Co-operation and Development (OECD) countries (Lane, 2020). For many students in the study, internet quality allowed for online interactions to occur. 
Students were asked to indicate what level of experience they had with online learning before the COVID-19 virus by completing a Likert scale with 1 being none and 10 being a great deal. The results of this are shown in Figure 3.

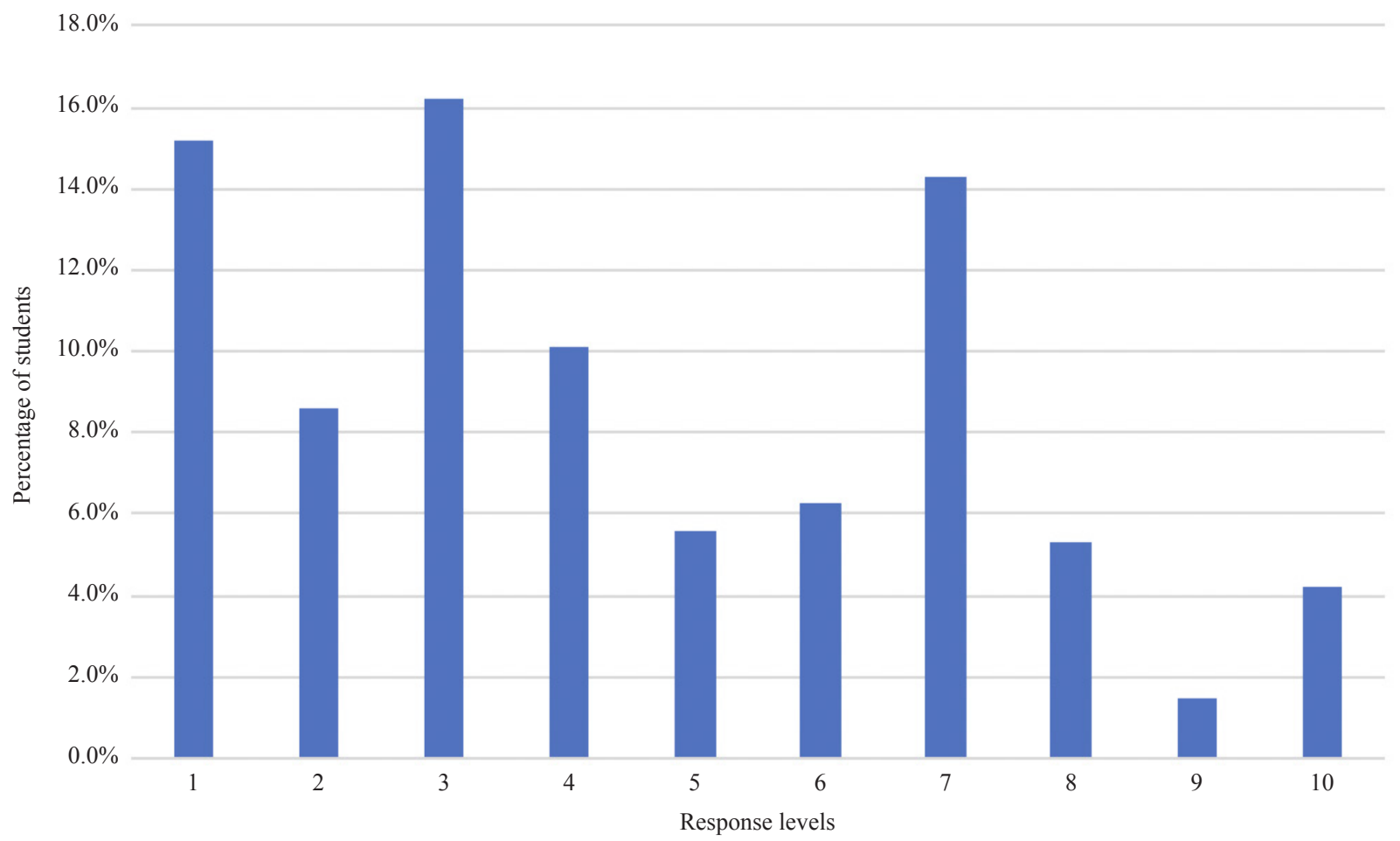

Figure 3. Online learning experience pre-COVID-19

As indicated in Figure 3, there is a wide range of experiences, with more students reporting lower levels of online learning than higher levels. This indicates that there would have been a substantial shift for the majority of students to $100 \%$ online learning making the process challenging. This would have been compounded by those students with poor internet connections and those who did not own their own device.

\subsection{Social presence}

In understanding one of the factors that might impact social presence, the aspects of how long students spent online both with their teachers and with one another were considered. It is important to note the quantity of time spent online does not only reflect social presence, but it does illustrate a change compared to in-class time. The difficult-to-quantify quality of interactions is also important. Figure 4 illustrates the total amount of time across each school students reported they interacted with their teachers each day.

As evident in Figure 4, students on average spent approximately 10 to 20 minutes online with their teachers each day across most schools. This represents a dramatic decrease in time compared to the five hours they would normally spend with their teachers each day.

Also of significance is the time students spent interacting with each other. Figure 5 sets out how long students interacted with each other each day about aspects related to schoolwork.

As illustrated in Figure 5, students also spent on average approximately 10 to 20 minutes interacting with each other about schoolwork during school time. This limited time for interactions reduced opportunities for the social chat to maintain a social presence. The importance of social chat online for students has been recognised. For example, in one Australian study, it was found that that "social interactions is an important precursor to more formal curriculum-related discussions" (Maher, 2009, p. 515). The limited social interactions in the present study would have, therefore, reduced 
curriculum-related discussions.

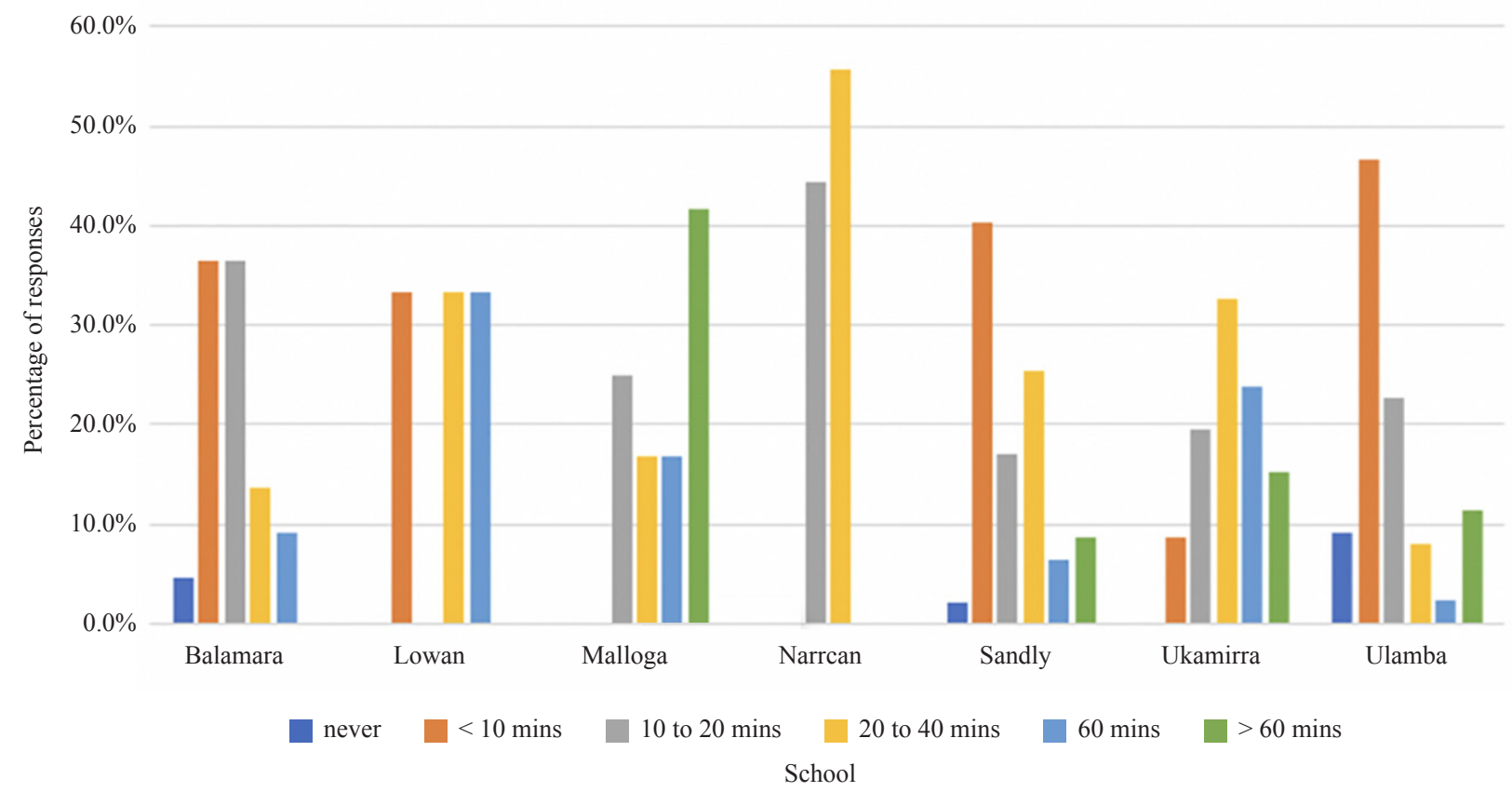

Figure 4. Amount of time each day students interacted with teachers

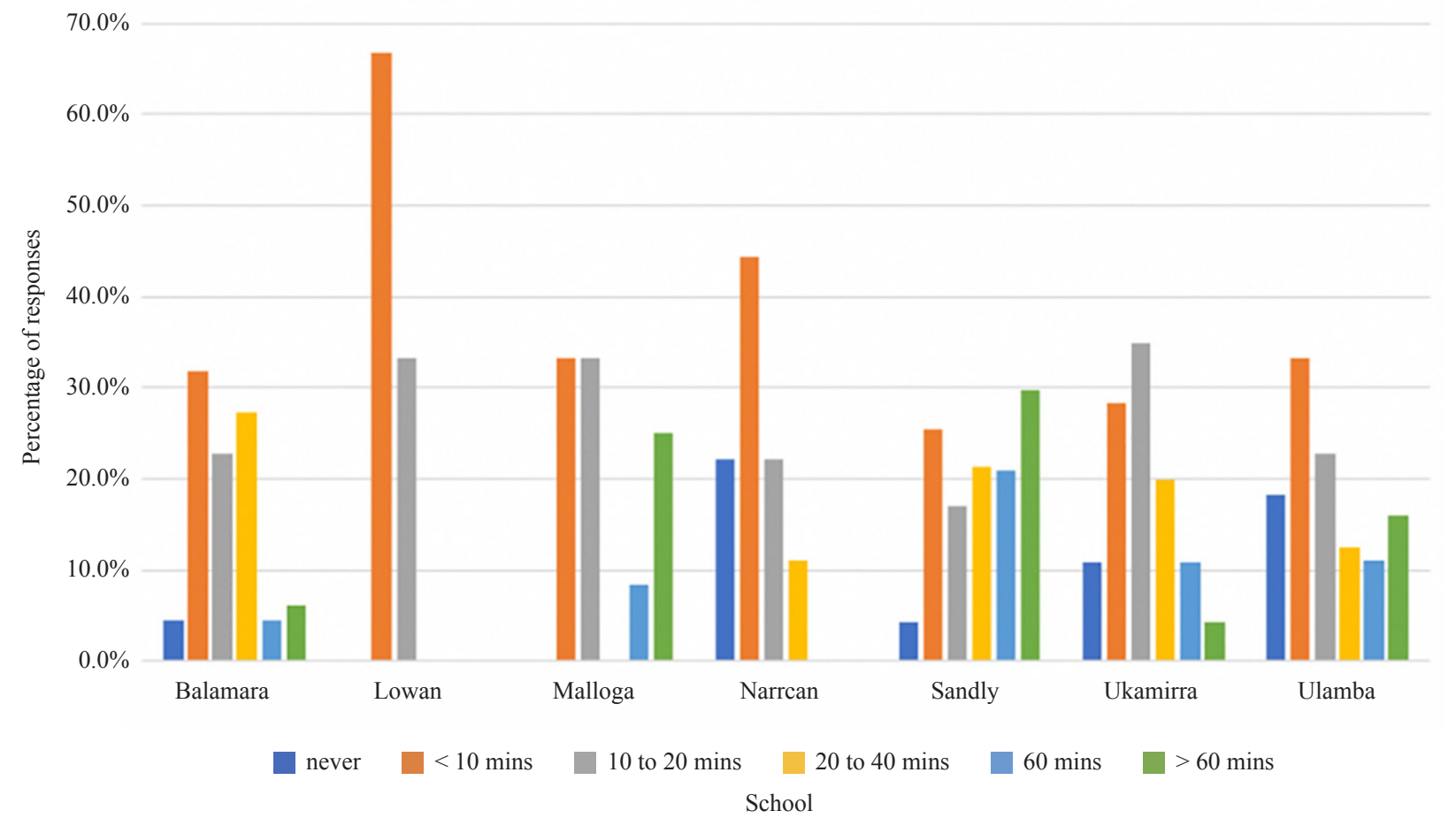

Figure 5. Amount of time each day students interacted with each other about schoolwork 
In analysing the written comments of the students, it was clear, with a response rate of $78 \%$, that their main concern was the greatly reduced level of social contact they had with one other, which impacted on social presence. Students were asked what they don't like about learning completely online. Some of the responses were:

- Not seeing my friends for a long time.

- Lack of social interaction.

Not only was it the absence of contact with friends that concerned students. Their lack of contact with teachers was also problematic as evident in the following survey responses relating to what they were looking forward to when going back to school.

- I love being able to see my teachers.

- Being able to see my friends and teachers have interesting, complex and intelligent conversations.

The desire to see teachers by students was consistent across all age groups with $48 \%$ commenting on this aspect.

The lack of social contact with the students was also commented on by teachers, with concerns including:

- Not seeing the kids-social/emotional and pastoral issues.

- lack of personal communication and relationship building with students.

Teachers in other studies have noted the negative impact on students' emotional wellbeing as a result of restrictions because of COVID-19. One impact reported was anxiety as a result of missing friends (Pikulski et al., 2020). As noted earlier, through this experience of missing friends, students would experience the feeling of disconnection (Ziebell et al., 2020). Such feelings would make it difficult to focus on school work.

Parents also commented on the social aspect:

- It's the social integration that my son has missed with both classmates \& teachers.

- Missed other students to discuss work.

Keeping social connections intact with friends and teachers has many benefits. For example: "Children who feel connected to their teachers and classmates have greater intrinsic motivation for learning and are more engaged" (Madill et al., 2014, p. 86). Additionally, children who thrive typically cultivate positive relationships with parents, peers, and teachers (Wentzel, 2002). This can include academic and emotional benefits. Whilst the cognitive aspect of learning was maintained during ERT, it appears that the social aspect faltered, which may have contributed to lower academic and poorer social outcomes (Hancock \& Zubrick, 2015).

In analysing qualitative responses, it was the physical face-to-face contact that students missed, as illustrated with these responses:

- Seeing and chatting with my friends in person.

- Being able to interact with people in person and asking for help is easier.

This absence of face-to-face interactions can lead to a reduced sense of instructor and peer presence (Bambara et al., 2009), which is not adequately filled by online interactions. This is particularly the case where schools close and students are uncertain about the future. Students in high school, whose social network consists of mainly their friends (and have fewer connections with family than younger students), would feel the loss particularly keenly. A lack of physical proximity has also been identified as concern and challenge for students and instructors when learning online in other studies (Robinson et al., 2017). It is thus important that teachers understand and address the psychosocial challenges of the pandemic (UNESCO, 2020), which should be a priority before teaching.

Whilst the social aspect of learning with peers was important, many participants indicated that online learning was less distracting. For example, a student commented when asked benefits of online learning that there were:

- No classmates to distract and annoy everyone.

This aspect of distraction was commonly commented on more by teachers and parents. Some comments by teachers were:

- For some removing the distractions of the classroom has improved their performance immensely.

- They are not distracted by poor behaviours.

Parents commented the most out of the three groups with comments like these:

- Good to be apart from other children who can be distractive also for each other's sake.

- Our children found learning easier without the distraction of misbehaving classmates.

Charles (1999) defines misbehaviour as "behaviour that is considered inappropriate for the setting or situation in which it occurs" (p. 2). Whilst responders did not specify what type of behaviour was problematic the effect was that it 
disrupted others.

Whilst social presence was diminished for students, a positive outcome of this for some students was the reduced interference from distracting students, which meant students could focus more on their schoolwork. This aspect has been found in other studies. In a survey conducted by Seidman (2005), it was found that disruptive behaviour amongst students was a major learning inhibitor for other students in the class. Carter et al. also found some parents prefer online learning for their children as it can minimise aspects such as bullying.

One aspect that impacted social presence was the restriction associated with working online as noted by all three groups. In commenting on this aspect, there are some comments on the use of VC.

One student commented:

- You do not get to see teachers and classmates in person, but you have to see them through a screen.

In an online environment, such as VC, vital aspects such as body language and facial expression can be more difficult to discern (Short et al., 1976). This, in turn, limits social presence. The use of VC was reported as being used by the majority of students and was responsible, in large part, for facilitating the synchronous interactions with students and teachers. There were concerns by teachers in regard to how well Zoom facilitated interactions as evident in this teacher's comment:

- When using Zoom it is hard to judge how students are understanding and engaging without body language. Very difficult to engage in sophisticated conversations.

This lack of sophisticated conversations was one of the reasons that teachers were not able to provide as much feedback as would have happened in the classroom. As noted by Shuell (1992), feedback is an essential part of meaningful learning. Without the opportunities for feedback by teachers, the learning experience would have been diminished for the students.

\subsection{Cognitive presence}

Teachers and students were asked about the process of learning online. Teachers were asked how well they believed students learnt online based on their experiences. As can be seen in Figure 6, a majority of teachers believed it was a positive experience.

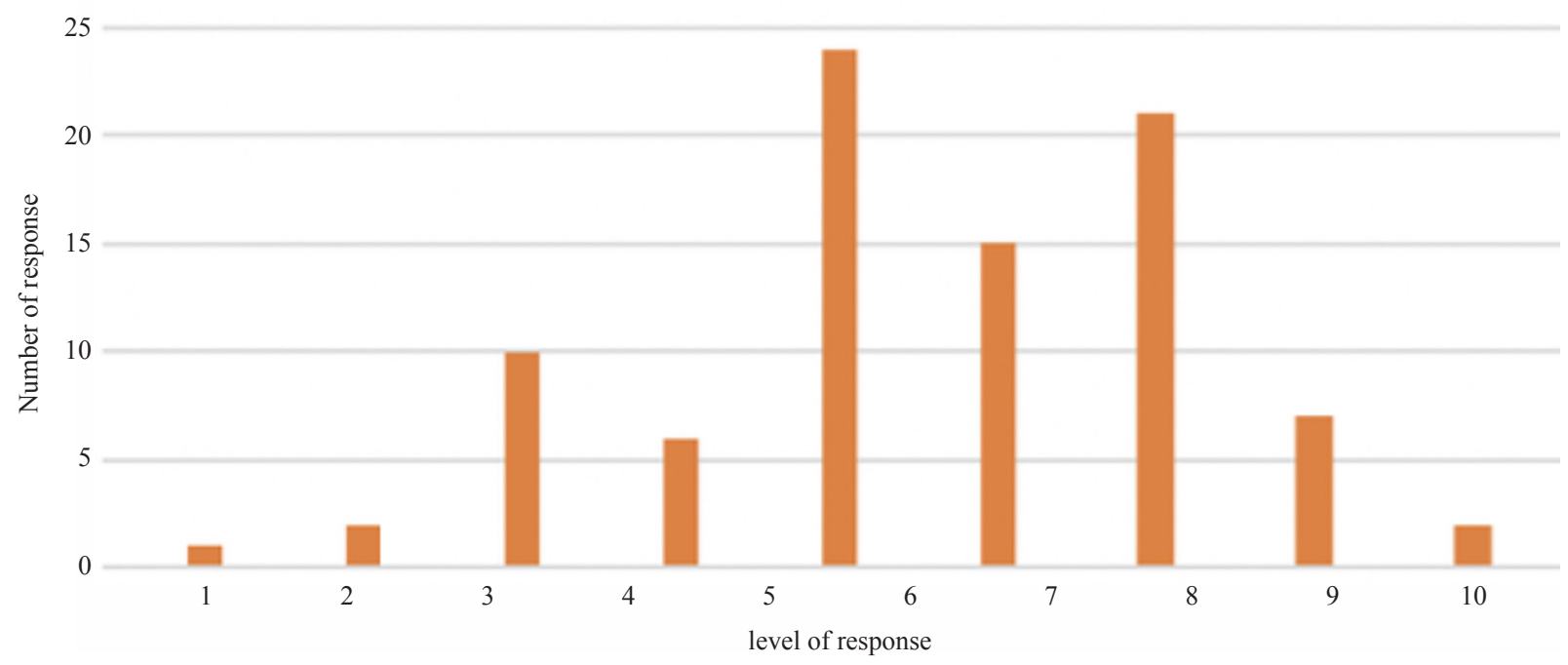

Figure 6. How well teachers believe students learn with classes being completely online

Figure 6 illustrates mixed opinions about the efficacy of online learning. This result is similar to that in a study conducted in Australia and New Zealand where it was found: "Teachers were divided about the efficacy of online learning, with almost equal numbers responding they were 'confident' and 'not confident' about it" (Flack et al., 2020, p. 
$3)$.

Students were asked how well they understood expectations via online learning. As can be seen in Figure 7, the majority of students were confident about their understanding.

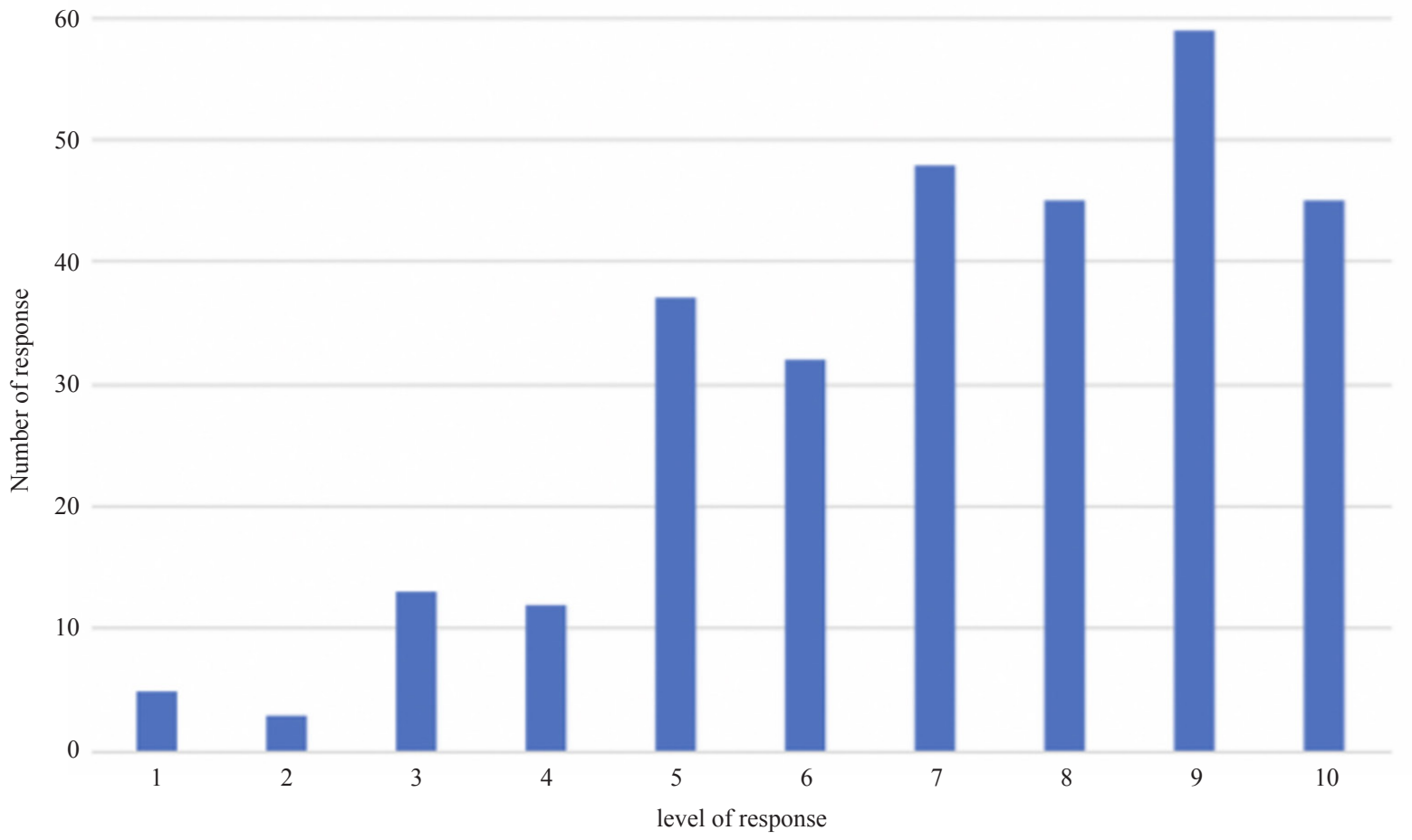

Figure 7. Students understanding of expectations of learning online

Comments posted by students in the survey reflected this high level of understanding:

- I understand what is being expected and that I need to attend all classes.

- My teacher's instructions are clear and I understand what is expected of me every day.

Students were asked about what schoolwork they had been learning online and teachers were asked what content they had been covering with students. The majority of students and teachers indicated that the content being covered was what would have been normally covered in a face-to-face setting. A comment by one student illustrates this:

- I have been learning a range of different subjects including those set by other teachers. For example, science, music, history, library and geography as well as maths, English and sport taught by my normal teacher.

Having a structure relating to content and expectations is important as noted by Reimers and Schleicher (2020) who state: "It is imperative to support forms of organization that provide students time to engage in predictable and structured learning opportunities" (p. 4). However, adjustments do need to be made given the restrictions of the online medium, which include lack of resources (both physical and online) and the absence of face-to-face teaching and learning. There were some comments by teachers which indicated adjustments had been made because of the sudden move to online teaching and learning as indicated by these responses by teachers:

- For English, I and my colleagues have adhered, with some 'downsizing', to the curriculum.

- We chose modules that were more suited to online learning-i.e. modules that were more research-oriented and less practical.

Another teacher indicated that the learning was more theoretically based, rather than practically based. This response was mirrored by students with these types of comments:

- I like to do things more hands-on and active or maybe watch some videos instead of reading.

- Can't do hands-on practicals e.g. science experiments. 
- I found the work from home harder because I like to learn visually and hands-on.

There is evidence that the questions or activities "play an important role in the type of cognitive activity evident in the discussions" (Garrison, 2007, p. 65-66). When questions or activities specifically require students to engage in practical tasks (e.g., hands-on), the outcome is cognitively better (Garrison, 2007). Therefore, whilst theoretical tasks (e.g., book work) do allow for completion of work by students individually, cognitively the outcome is not as beneficial as practical tasks, particularly for younger and less-abled students.

In addition to learning the school content, the teachers provided instructions on how to use tools in the online environment as illustrated in this quote:

- There is the explicit teaching of students to use new online tools (Mathspace, Zoom, converting their photos of documents to PDF, uploading their videos to YouTube).

A move to $100 \%$ online course delivery means that students need to develop new skills in how to use the online spaces. As their move to the online environments happened quickly, students were not provided with instruction on how to work online before the move. This meant the students would have needed instruction in the use of the online tools such as mentioned above whilst online. Given that teacher presence was reduced, this would have made it difficult for many students to work in the online environments.

One cognitive benefit reported by $25 \%$ of students was that they could work at their own pace.

- I can wake up at a later time, do things at my own pace, be comfortable while working.

At home, I could work at my own pace and do things when I liked.

This aspect was also reported by many teachers:

- Students can complete set work in their own time preferences.

- It is great for students who are self-directed as it allows them to go through the work at their own pace.

Parents too (20\%), commented on this aspect:

- The online learning suits my daughter as she can work at her own pace.

Whilst there were a number of disadvantages identified by participants in learning from home, as noted by the comments above, one of the benefits was that students had more control over their own learning. As identified in the literature review and evident in the data in this study, students were able to set their own pace and time of learning (Huang et al., 2009). Students could choose the order in which they completed their studies and how long they spent on each subject or task. However, this did not work for all students. It worked well for students who were self-directed learners, but for those students who were not self-directed, they tended to struggle. This aspect exasperated the potential of digital inequality as raised by Williamson et al. (2020). Whilst the students had digital access, those who struggled with direction and motivation during normal times would have found the move to an online environment challenging. This would have been further exasperated if those students did not have access to technology and their parents were not techsavvy.

Providing learning opportunities was more challenging for teachers of younger students because of their limited abilities to undertake self-directed learning. Teachers' comments included:

- Students who are a younger struggle.

- Year-2 students are quite young and are still learning to read independently. I had to provide voice-over instructions for every single task and voice-over feedback.

As noted by Herrington et al. (2003), the capacity of the learning environment to encourage independent learning is an important factor for successful online learning. Part of this environment would include teachers providing verbal support, as noted by the teacher in a comment above as in grade 2 and below can struggle following written instructions. Younger students generally do not have the capacity to plan their day independently and if they do not understand set work, they do not benefit from interactive feedback from teachers. Given the limited teaching presence, cognitive presence was limited for younger students.

Given only students in year-4 and above completed the survey, younger students' opinions are not represented. Given the COVID-19 restrictions, it was not possible to speak with younger students about their experiences. This is a methodological weakness of online surveys for young students in this project.

Another aspect reported by students (15\%) was that they had more work online compared to face-to-face learning.

- I do not like that some teachers are giving us more work as they cannot tell just how much we will really get through during class time. 
- I understand the work but I feel that sometimes the teachers are giving us too much work and it is not possible to get through all of it in time.

This extra workload resulted in students getting behind in their work as illustrated by these comments by the students:

- I find myself falling behind in some of the work as I am trying to complete the work from a previous lesson that I didn't finish and so can't do the work for the next class.

- There is a lot more work than there would normally be so sometimes I spend 3 hours finishing work for a subject so I end up falling behind.

The data from this study suggest that reduced cognitive presence limited teachers' understanding of the work their students were completing. Given that students spent less time with teachers, they were not able to complete their work effectively and this, in turn, slowed down the rate at which they could complete it. Also, teachers' inexperience working in an exclusively online environment meant that they would not be able to successfully gauge how much work would be suitable for their students.

\subsection{Teaching presence}

As noted earlier, the first aspect of teaching presence involves the design of the educational experience, including the selection, organisation, and presentation of the course content. Teachers were asked about their experience with teaching online. The results are shown in Figure 8.

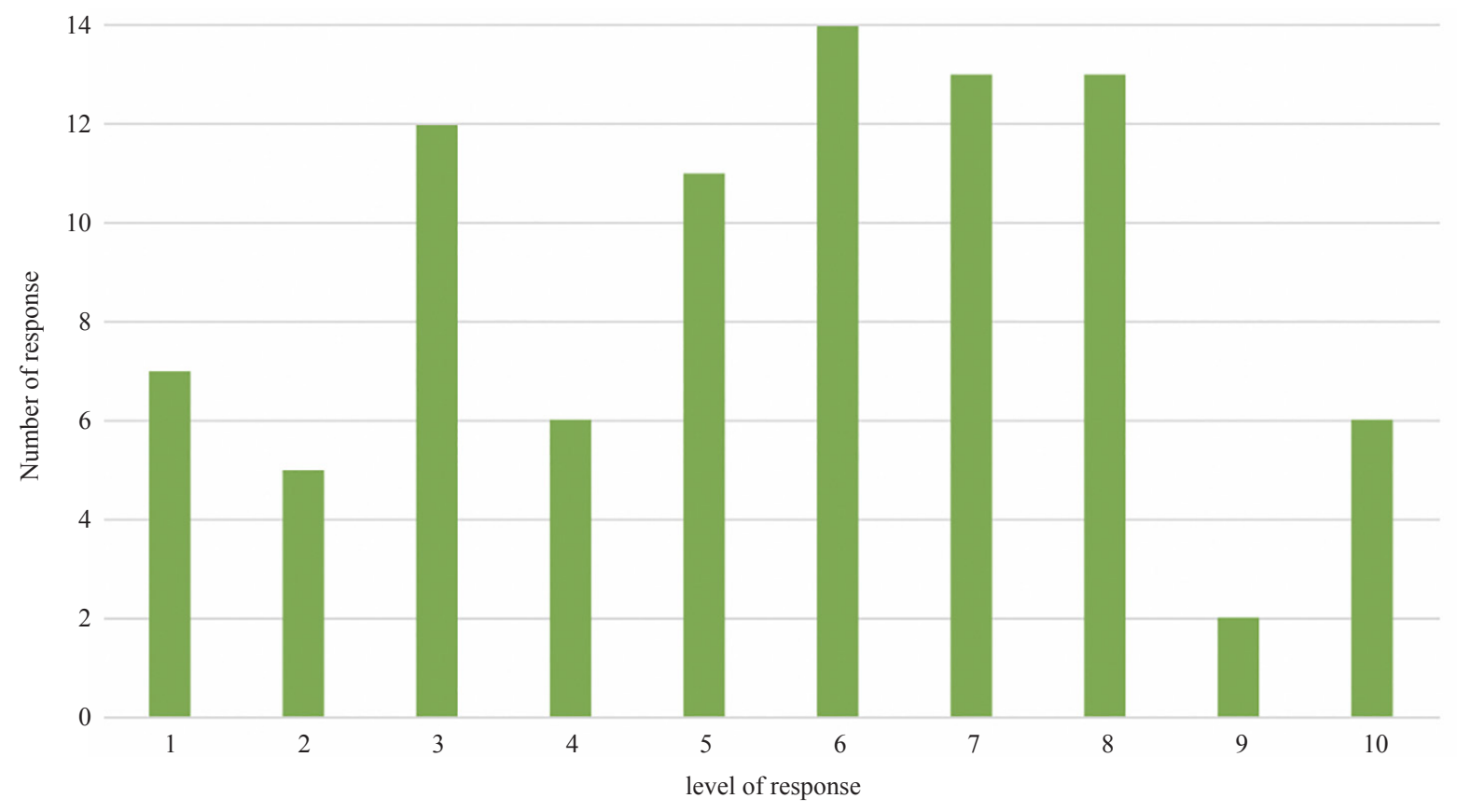

Figure 8. Teacher experience with online learning

As indicated in Figure 8, a majority of teachers had experience with online learning, but whilst not shown in Figure 8 , they had no experience facilitating emergency remote teaching as this was not anything they had been required to do previous to the pandemic.

One of the biggest issues reported in relation to teaching presence was low levels of students' motivation and engagement. When asked about what some of the challenges in learning at home were, these were some comments by students:

- I don't have any motivation to do any school work, so most of it is left undone. 


\section{- Being motivated and understanding and retaining information.}

Student engagement and motivation are vital to academic achievement. Engaged students are attentive and participate in discussions, exert effort in activities, and exhibit interest and motivation to learn (Fredricks et al., 2004). On the other hand, students who are not engaged are more passive learners and report being bored and anxious (Reyes, 2014). Activities that engage and motivate students whilst in lockdown are, therefore, as important as the schoolwork that they complete.

Teachers also commented on engagement and motivation as evident in these responses:

- The challenge of having students at home was that it was difficult to support students who were not engaging in online learning.

- It is harder to keep them motivated online and not being there to give them immediate help and feedback led to some of them becoming disengaged.

Responses from students also indicated there were problems in relation to communication with teachers:

- Sometimes when I typed a question to my teacher they didn't respond.

- It's harder to ask teachers questions.

As the responses above suggest, and the limited amount of time students interacted with teachers, limited feedback did lead to students being unmotivated. This is in line with research where it is shown teacher feedback directly relates to student motivation (Hosler \& Arend, 2012) and that students will invest more into their schoolwork if motivated (Peetsma \& Van der Veen, 2015). However, other research has also found that high levels of teaching presence do not always guarantee high student motivation (Cole et al., 2017). From a community of inquiry perspective, high levels of social and cognitive presence would also need to be in place for high levels of motivation to be present.

Teachers recognised the challenge of motivating students as evident in these responses:

- I feel that I have required students to be more autonomous in their learning and that this has been an issue for students who are un/undermotivated.

- Some students either didn't engage or did a bare minimum. It was difficult to motivate them.

It appears that in designing the online content, that insufficient consideration was given to feedback and how and when it might be provided. As noted in the first comment above by a teacher, there was an expectation for students to become more autonomous. This is difficult for younger students.

A significant number of parents reported on issues concerning motivation. Comments included:

- Some days were terrible, she didn't want to do any work and I had to spend the day trying to motivate her.

- Keeping them engaged and ensuring they were actually learning was a challenge.

Wentzel (1998) argues that highly-motivated students are simply well-adjusted individuals who also enjoy supportive relationships with their parents. The role of parents was important during the lockdown as it was expected they would provide support, supplement the teachers' work, and provide in part, motivation.

Parents were asked how they helped their children with homework before the COVID period. This response is typical of a majority of responses from parents of high school students:

- I had little involvement, I would always ask what she was working on and we would talk about class but unless she told me she had assignments due I didn't know.

Many of the students in this study were in secondary school and parental involvement in their schoolwork was limited as indicated in the parent's quote. Additionally, the level of parental involvement decreases dramatically as children move into secondary school (Epstein, 2005) so parents of secondary school students would generally have been unprepared for this challenge.

Given the amount and scope of change for the students, it is argued here that the support from parents needed to have increased in order to help their children stay motivated and engaged as teaching presence reduced. Having stated this, parents had a number of challenges faced, including their own work commitments and limited understanding of school content. These challenges limited the support they could provide.

An additional consideration regarding parental support is the impacts of COVID-19 on their own work commitments and thus their ability to support the education of their children at home. As noted by Karakose et al. (2021), the "blurring of the boundaries between work and non-work can pave the way for conflicting work and family demands" (p. 14). Such demands affect the ability of parents to offer to provide support. 


\section{Conclusions}

The results of the study indicate that internet technology was able to mediate interactions and thus support learning to some extent. As was demonstrated, student ownership of computers was generally high, and whilst the internet quality was mixed, it was also generally high. There were a number of negative impacts of students learning completely online. The biggest reported impact, particularly by students, was a lack of social presence. Teachers also noted this absence.

There were challenges faced by students in this study where they were impacted socially, and this resulted in a loss of motivation and engagement. More time for supporting this social aspect to cultivate social connections between teachers and students, and between students would have resulted in more social cohesion. It is acknowledged that these were very challenging times and that teachers were working to support the educational and social needs of their students.

Some parents reported that the lack of social presence meant fewer distractions for their children. Lack of social presence was driven by reduced hours of contact between students and teachers and of the limitations of interacting in an online environment, such as lack of cues normally present in face-to-face learning. One of the important outcomes of this study is an understanding of the need for teachers to understand more fully, and respond to, the social aspects of learning and prioritise these over the cognitive aspects of schooling.

In examining cognitive presence, students' understanding of work in an online environment was reported to be sound, although teachers were less positive about working in an online environment. The work students were being provided with was reported to be similar to what they would be provided within a classroom although some students reported an increase in the amount of work. Additionally, students noted an increase in theoretical work at the expense of less practical work. Some feedback by teachers indicates that the curriculum was modified to accommodate online learning. There were some comments about supporting students to use online tools, but this was limited and contributed to reduced teaching presence. An advantage of working online was that students could pace the work to suit them, but this only suitable for students who were self-directed. This suggests in working in an online environment, that teachers should have good knowledge of their students' capabilities so they can provide appropriate support.

In relation to teaching presence, there were variations in teachers' experience in working in an online environment. No teacher had experience with emergency relief teaching, and this impacted their knowledge and ability to support online learning during the pandemic. One of the biggest impacts reported by students was a lack of motivation and engagement, which was also commented on by teachers and parents. As noted, this aspect is as important as curriculum content, particularly where uncertainty existed because of the pandemic. Whilst there were some difficulties and uncertainties reported with the move to online learning, the speed that this was done is a testimony to the hard work of the teachers.

\section{Limitations and future work}

This research was conducted during a period when impacts of COVID-19 were being felt in schools. As a result of this, there was a relatively small sample size, which does not necessarily represent the broader educational community. Not as many teachers as was hoped participated in the study due to the extra workload they were under adopting work for the students. Lastly, whilst the study represents both primary and secondary school students, the number of primary school students represented in the study is low.

It is hoped that another event such as was experienced in schools as a result of COVID-19 does not occur again, as such research into school communities that suddenly transition to a completely online environment may not be required. However, there is further research that can be undertaken looking at the use of online learning in blended learning environments or where students only ever work with other students online such as in the school of the air in Australia.

\section{Funding details}

The project for which this paper was produced was not funded. 


\section{Disclosure statement}

There are no conflicts of interests to report.

\section{References}

Ahmed, A. (2020). Synchronizing pedagogy and technology in post COVID scenario. International Journal of Creative Research Thoughts, 8(6), 243-246. https:/www.researchgate.net/publication/341988034_Synchronizing Pedagogy_and_Technology_in_Post_COVID_Scenario

Anderson, T., Rouke, L., Garrison, D. R., \& A Archer, W. (2001). Assessing teaching presence in a computer conferencing context. Journal of Asynchronous Learning Networks, 5(2), 1-17. https://citeseerx.ist.psu.edu/ viewdoc/download?doi=10.1.1.95.9117\&rep=rep1\&type=pdf

Audet, J., \& d'Amboise, G. (2001). The multi-site study: An innovative research methodology. The Qualitative Report 6(2), 1-18. https://doi.org/10.46743/2160-3715/2001.2001

Australian Bureau of Statistics. (2018). Household use of information technology, Australia, 2016-17. Canberra, Australian Bureau of Statistics. https://www.abs.gov.au/ausstats/abs@.nsf/mf/8146.0

Bambara, C. S., Harbour, C., Davies, T., \& Athey, S. (2009). Delicate engagement: The lived experience of community college students enrolled in high-risk online courses. Community College Review, 36(3), 219-238. https://eric. ed.gov/?id=EJ823181

Belderrain, Y. (2006). Distance education trends: Integrating new technologies to foster student interaction and collaboration. Distance Education, 27(2), 139-153. https://doi.org/10.1080/01587910600789498

Biocca, F., Harms, C., \& Gregg, J. (2001, January). The networked minds measure of social Presence: Pilot test of the factor structure and concurrent validity. Media Interface \& Network Design Labs. https://www.semanticscholar. org/paper/The-Networked-Minds-Measure-of-Social-Presence-\%3A-of-Biocca-Harms/784977a00148ea24e1a65e6 $160823305 \mathrm{a} 2 \mathrm{ceb} 95 \mathrm{c}$

Bourke, B. (2019). Using gamification to engage higher-order thinking skills. In J. Keengwe (Ed.), Handbook of Research on Promoting Higher-Order Skills and Global Competencies in Life and Work (pp. 1-21). IGI Global. DOI: 10.4018/978-1-5225-6331-0.ch001

Boyatzis, R. E. (1998). Transforming qualitative information: Thematic analysis and code development. SAGE Publications. https://us.sagepub.com/en-us/nam/transforming-qualitative-information/book7714

Cahapay, M. B. (2020). Rethinking education in the new normal post-COVID-19 era: A curriculum studies perspective. Aquademia, 4(2), 1-5. https://doi.org/10.29333/aquademia/8315

Carter Jr, R. A., Rice, M., Yang, S., \& Jackson, H. A. (2020). Self-regulated learning in online learning environments: strategies for remote learning. Information and Learning Sciences, 121(5-6), 321-329. https://www.emerald.com/ insight/content/doi/10.1108/ILS-04-2020-0114/full/html

Charles, C. M. (1999). Building classroom discipline. Addison Wesley Longman, Inc. https://www.worldcat.org/title/ building-classroom-discipline/oclc/38030289

Charmaz, K. (1993). The grounded theory method: An explanation and interpretation. In R. Emerson (Ed.), Contemporary field research (pp. 109-126). Boston: Little Brown.

Cole, A., Anderson, C., Bunton, T., Cherney, M., Fisher, V. C., Featherston, M., Motel, L., Peck, B., \& Allen, M. (2017). Student predisposition to instructor feedback and perceptions of teaching presence predict motivation toward online courses. Online Learning Journal, 21(4), 245-262. https://eric.ed.gov/?id=EJ1163451

Di Pietro, G., Biagi, F., Costa, P., Karpinski, Z., \& Mazza, J. (2020). The likely impact of COVID-19 on education: Reflections based on the existing literature and recent international datasets (No. JRC121071). Joint Research Centre (Seville site). doi:10.2760/126686

Epstein, J. L. (2005). Attainable goals? The spirit and letter of the No Child Left Behind Act on parental involvement. Sociology of Education, 78(2), 179-182. https://doi.org/10.1177/003804070507800207

Flack, C. B., Walker, L., Bickerstaff, A., Earle, H., \& Margetts, C. (2020). Educator perspectives on the impact of COVID-19 on teaching and learning in Australia and New Zealand. Pivot Professional Learning. https://pivotpl. com/wp-content/uploads/2020/04/Pivot_StateofEducation_2020_White-Paper-1.pdf

Fredricks, J. A., Blumenfeld, P. C., \& Paris, A. H. (2004). School engagement: Potential of the concept, state of the evidence. Review of Educational Research, 74, 59-109. https://doi.org/10.3102/00346543074001059

Gares, S. L., Kariuki, J. K., \& Rempel, B. P. (2020). Community matters: Student-instructor relationships foster student 
motivation and engagement in an emergency remote teaching environment. Journal of Chemical Education, 97(9), 3332-3335. https://doi.org/10.1021/acs.jchemed.0c00635

Garrison, D. R. (2007). Online community of inquiry review: Social, cognitive, and teaching presence issues. Journal of Asynchronous Learning Networks, 11(1), 61-72. https://eric.ed.gov/?id=EJ842688

Garrison, D. R., Anderson, T., \& Archer, W. (2000). Critical inquiry in a text-based environment: Computer conferencing in higher education. The Internet and Higher Education, 2(2-3), 87-105. https://doi.org/10.1016/ S1096-7516(00)00016-6

Garrison, D. R., Anderson, T., \& Archer, W. (2001). Critical thinking and computer conferencing: A model and tool to assess cognitive presence. American Journal of Distance Education, 15(1), 7-23. https://auspace.athabascau.ca/ bitstream/handle/2149/740/critical_thinking_and_computer.pdf?sequence=1\&isAllowed=y

Garrison, D. R., \& Arbaugh, J. B. (2007). Researching the community of inquiry framework: Review, issues, and future directions. The Internet and Higher Education, 10(3), 157-172. https://doi.org/10.1016/j.iheduc.2007.04.001

Hancock, K. J., \& Zubrick, S. R. (2015). Children and young people at risk of disengagement from school. Commissioner for Children and Young People Western Australia. https://www.ccyp.wa.gov.au/media/1422/reporteducation-children-at-risk-of-disengaging-from-school-literature-review.pdf

Hennink, M., Hutter, I., \& Bailey, A. (2011). Qualitative research methods. SAGE Publications Ltd. https://www. worldcat.org/title/qualitative-research-methods/oclc/456839972

Herrington, J., Oliver, R., \& Reeves, T. C. (2003). Patterns of engagement in authentic online learning environments. Australasian Journal of Educational Technology, 19(1), 59-71. DOI: https://doi.org/10.14742/ajet.1701

Hodges, C., Moore, S., Lockee, B., Trust, T., \& Bond, A. (2020, March 27). The difference between emergency remote teaching and online learning. Educause Review. https://www.semanticscholar.org/paper/The-Difference-BetweenEmergency-Remote-Teaching-Hodges-Moore/14e6b1ab3e998b4ec856b12ae0f190ff86a51207\#paper-header

Hosler, K. A., \& Arend, B. D. (2012). The importance of course design, feedback, and facilitation: Student perceptions of the relationship between teaching presence and cognitive presence. Educational Media International, 49(3), 217-229. https://eric.ed.gov/?id=EJ985904

Huang, R. M., Lanqin, Z., \& Haisen, Z. (2009). The theory of curriculum design based on blended learning. Education Research, 1, 9-14. https://doi.org/10.1007/978-3-540-85170-7_6

Karakose, T., Yirci, R., Papadakis, S. (2021). Exploring the interrelationship between covid-19 phobia, work-family conflict, family-work conflict, and life satisfaction among school administrators for advancing sustainable management. Sustainability, 13(15), 8654. DOI: 10.3390/su13158654

Lane, I. (2020). Embarrassingly slow: Australia's broadband internet ranked fourth slowest in OECD. The New Daily. https://thenewdaily.com.au/life/tech/2020/01/28/broadband-speeds-australia-oecd/

Lee, V., \& Wagner, H. (2002). The effect of social presence on the facial and verbal expression of emotion and the interrelationships among emotion components. Journal of Nonverbal Behavior, 26(1), 3-25. https://link.springer. com/article/10.1023/A:1014479919684

Lincoln, Y., \& Guba, E. (1985). Naturalistic Inquiry. Sage Publications. https://us.sagepub.com/en-us/nam/naturalisticinquiry/book842

Lowenthal, P. R., \& Parscal, T. (2008). Teaching presence. The Learning Curve, 3(4), 1-2. https://patricklowenthal.com/ teaching-presence/

Madill, R. A., Gest, S. D., \& Rodkin, P. C. (2014). Students' perceptions of relatedness in the classroom: The roles of emotionally supportive teacher-child interactions, children's aggressive-disruptive behaviors, and peer social preference. School Psychology Review, 43(1), 86-105. https://doi.org/10.1080/02796015.2014.12087456

Maher, D. (2009). The importance of elementary school students' social chat online: reconceptualising the curriculum. Computers and Education, 53(2), 511-516. https:/www.semanticscholar.org/paper/The-importance-of-elementaryschool-students'-chat-Maher/863c0f04db725eb446c38a2db8d048c56ee0577a

Mason, J. (2002). Researching your own practice: The discipline of noticing. Routledge.

Nunan, D. (1992). Research methods in language learning. Cambridge University Press.

Peetsma, T., \& Van der Veen, I. (2015). Influencing young adolescents' motivation in the lowest level of secondary education. Educational Review, 67(1), 97-120. https://doi.org/10.1080/00131911.2013.830593

Pikulski, P., Pella, J., Casline, E., Hale, A., Drake, K., \& Ginsburg, G. S. (2020). School connectedness and child anxiety. Journal of Psychologists and Counsellors in Schools, 30(1), 13-24. https://doi.org/10.1017/jgc.2020.3

Reimers, F. M., \& Schleicher, A. (2020). A framework to guide an education response to the COVID-19 pandemic of 2020. OECD. https:/www.aforges.org/wp-content/uploads/2020/04/framework.pdf

Rich, G. (2020, May 13). During the 1918 flu pandemic, at-home learning meant little schoolwork. Washington Post. https://www.washingtonpost.com/lifestyle/kidspost/School-during-the-1918-spanish-flu- 
pandemic/2020/05/12/7d606c90-7f32-11ea-9040-68981f488eed_story.html

Robinson, H. A., Kilgore, W., \& Warren, S. J. (2017). Care, communication, learner support: Designing meaningful online collaborative learning. Online Learning, 21(4), 29-51. doi:10.24059/olj.v21i4.1240

Sandelowski, M. (2000). Focus on research methods-whatever happened to qualitative Description? Research in Nursing and Health, 23(4), 334-340. https://doi.org/10.1002/1098-240X(200008)23:4<334::AID-NUR9>3.0.CO;2-G

Shuell, T. J. (1992). Learning theory and instructional design: Engaging the learner in meaningful ways. Asia Pacific Journal of Education, 12(2), 1-10. https://doi.org/10.1080/02188799208547687

Seidman, A. (2005). The learning killer: Disruptive student behavior in the classroom. Reading Improvement, 42(1), 4047. https://eric.ed.gov/?id=EJ711792

Short, J., Williams, E., \& Christie, B. (1976). The social psychology of telecommunications. John Wiley \& Sons. https:// www.worldcat.org/title/social-psychology-of-telecommunications/oclc/2585964

UNESCO. (n.d.). Education: From disruption to recovery. https://en.unesco.org/covid19/education response

UNESCO. (2020). 10 recommendations to ensure that learning remains uninterrupted. https://en.unesco.org/news/ covid-19-10-recommendations-plan-distance-learning-solutions

Wentzel, K. R. (2002). Are effective teachers like good parents? Teaching styles and student adjustment in early adolescence. Child Development, 73(1), 287-301. DOI: 10.1111/1467-8624.00406

Wentzel, K. R. (1998). Social relationships and motivation in middle school: The role of parents, teachers, and peers. Journal of educational psychology, 90(2), 202-209. https://doi.org/10.1037/0022-0663.90.2.202

Wiersma, W., \& Jurs, S. G. (2005). Research methods in education. Pearson. https://www.worldcat.org/title/researchmethods-in-education-an-introduction/oclc/54611191

Williamson, B., Eynon, R., \& Potter, J. (2020). Pandemic politics, pedagogies and practices: Digital technologies and distance education during the coronavirus emergency. Learning, Media and Technology, 45(2), 107-114. https:// doi.org/10.1080/17439884.2020.1761641

Ziebell, N., Acquro, D., Pearn, C., \& Seah, W. T. (2020). Australian Education Survey: Examining the Impact of COVID-19, Report Summary. Melbourne Graduate School of Education. https://findanexpert.unimelb.edu.au/ scholarlywork/1456468-australian-education-survey--examining-the-impact-of-covid-19-report-summary 